\title{
NEUROSSÍFILIS:
}

\section{UMA BREVE REVISÃO}

\section{Leonardo Caixetal ${ }^{1}$ Vânia Lúcia Dias Soares², Giane Divina Reis ${ }^{3}$, Jean Newton Lima Costa ${ }^{4}$ e Ana Caroline Marques Vilela ${ }^{5}$}

\section{RESUMO}

A neurossífilis (NS) designa todas as formas de comprometimento do sistema nervoso central (SNC) causadas pela bactéria Treponema pallidum. Em pacientes imunocompetentes, ocorre principalmente no estádio terciário da sífilis (embora suceda em outros estádios), acometendo apenas $10 \%$ dos pacientes com infecção primária não tratada. Apesar de um decréscimo significativo na incidência de neurossífilis nas últimas três décadas, a invasão do sistema nervoso humano ainda ocorre e a apresentação clínica não segue a evolução tradicional da era pré-antibiótica. Observa-se, atualmente, que a NS pode apresentar quadros clínicos muito similares aos de outras enfermidades do sistema nervoso, podendo ser confundida, mesmo após anos de acompanhamento, com doenças neurológicas ou psiquiátricas. Neste trabalho, fizemos uma revisão histórica, conceitual, epidemiológica, clínica e diagnóstica com o objetivo de ampliar o conhecimento sobre esta doença e melhorar a sua compreensão.

DESCRITORES: Neurossífilis; Treponema pallidum; paralisia geral progressive; demência.

\section{ABSTRACT}

Neurosyphilis: a brief review

Neurosyphilis (NS) designates all the adverse effects on the central nervous system (CNS) caused by Treponema pallidum. It occurs at the third stage of syphilis in about $10 \%$ of patients with untreated primary infection. Despite a significant decrease in the incidence of neurosyphilis during the last three decades, the invasion of the human nervous system still takes place and the clinical presentation does not follow the traditional evolution of the pre-antibiotic era. At present, it is observed that NS

1 Instituto de Patologia Tropical e Saúde Pública (PTSP) da Universidade Federal de Goiás (UFG), Goiânia, Brasil.

2 Programa de Pós-Graduação em Medicina Tropical, IPTSP, UFG, Goiânia, Brasil.

3 Campus de Jataí, UFG, Jataí, Brasil.

4 Universidade de Brasília, Brasília, Brasil.

5 Programa de Pós-Graduação em Ciências da Saúde, UFG, Goiânia, Brasil.

Endereço para correspondência: leonardocaixeta1@gmail.com

Recebido para publicação em: 3/2/2014. Aceito em: 19/3/2014. 
may present clinical features very similar to those of other illnesses of the nervous system, and can be mistaken, even after years of follow-up, for neurological or psychiatric illnesses. In this work, we conducted an historical, epidemiological, conceptual, clinical and diagnostic review, with the purpose of expanding the knowledge and improving the understanding of this disease.

KEY WORDS: Neurosyphilis; Treponema pallidum; progressive general paralysis; dementia.

\section{INTRODUÇÃO}

Neste trabalho buscamos revisar brevemente a literatura científica quanto aos aspectos mais importantes das principais formas de comprometimento do sistema nervoso central (SNC) causadas pela bactéria Treponema pallidum.

Neurossífilis (NS) designa todas as diversas formas de comprometimento do SNC causadas por esta bactéria (Zhang et al., 2013). Em imunocompetentes, ocorre como manifestação terciária ou tardia da sífilis, mas pode ser observada na fase secundária e mesmo na primária. De fato, sabe-se que a bactéria Treponema pallidum invade, mais frequentemente, o SNC nas fases iniciais da infecção, verificando-se anormalidades do líquido cefalorraquidiano (LCR) em até $40 \%$ dos casos de sífilis secundária (Timmermans \& Carr, 2004). Nesta fase, a NS é usualmente assintomática ou se manifesta com leves sinais meníngeos; raramente podem ocorrer meningite aguda e acometimento de nervos cranianos. Mesmo sem tratamento, a infecção do SNC evolui para remissão e somente cerca de $10 \%$ dos indivíduos não tratados na fase primária da sífilis apresentam NS posteriormente. Mesmo nestes últimos, a infecção do SNC evolui assintomaticamente durante a fase latente da doença, podendo durar décadas (O’donnell \& Emery, 2005).

\section{HISTÓRICO}

Em fins do século XV, segundo Pagnano e Bechelli (1987), foram relatados os primeiros casos de sífilis no continente europeu, relacionados, segundo alguns, com a viagem de Colombo às Américas. Outros atribuíam a doença à mutação espontânea de uma espiroqueta, já presente no meio ambiente e adaptada ao homem, causando, no início, infecção não venérea e, depois, espalhando-se por transmissão sexual. Os autores citados reportaram-se a Ricord (1799-1889), grande sifilógrafo francês, que se opunha à teoria da origem americana da sífilis e reforçava a ideia da antiguidade do problema ao afirmar que a primeira sentença da Bíblia poderia ser: "Em princípio Deus criou o céu, a terra, o homem e as doenças venéreas", sugerindo sua existência desde o alvorecer dos tempos. Outro especialista francês do século XIX (Fournier, 1906) em seu Traité de la Syphilis, refere-se à doença pelo nome com o qual é universalmente conhecida até nossos dias. Em sua origem, isto é, quando invadiu a Europa nos últimos anos do século $\mathrm{XV}$, a doença foi denominada: Morbus gallicus, Caries gallica, mal francês, mal napolitano, mal castelhano, mal português, etc. É interessante ressaltar que os 
diversos povos referiam-se a ela e a nominavam, mas atribuíam-na aos povos vizinhos, rejeitando a paternidade da doença.

A história da neurossífilis ou neurolues inicia-se logo após a primeira epidemia de sífilis que assolou a Europa na última década do século $\mathrm{XV}$, porém, até fins do século XVIII, era considerado raro o envolvimento do sistema nervoso pela moléstia (Ghanem, 2010). Por sua vez, Gastal et al. (1999) afirmaram que Bayle, em 1822, foi o primeiro a definir a paralisia geral como uma entidade clínica, descrevendo-a como secundária a uma inflamação da membrana aracnoide.

A paralisia, segundo Fournier (1879), está relacionada com a etiologia sifilítica. O autor inseriu-a no grupo das "paralisias" em razão do seu caráter tardio e inconstante na patologia da afecção, mas não demonstrou formalmente sua natureza sifilítica. A demonstração inconteste da etiologia da neurossífilis aconteceu somente em 1913 quando Noguchi e Moore, citados por Nitrini (1981) identificaram Treponema pallidum no parênquima cerebral de pacientes com paralisia geral progressiva (PGP).

\section{EPIDEMIOLOGIA}

A incidência de NS caiu drasticamente em meados do século XX após o advento da penicilina. Nos Estados Unidos, por exemplo, a taxa de primeiras internações nos hospitais psiquiátricos por NS caiu de 4,3 por 100.000 habitantes, em 1946, para 0,4 por 100.000 em 1960 (Davis, 2008).

Nos últimos anos, entretanto, o número de casos notificados de sífilis em fase inicial aumentou tanto em indivíduos sem comprometimento imunológico quanto, em especial, naqueles infectados pelo vírus da imunodeficiência adquirida (HIV). Existe lógica em esperar um aumento nos casos de sífilis tardia, inclusive NS. Observa-se também um desvio na forma de apresentação clínica da NS de uma lesão parenquimatosa, atualmente bem rara, para a forma de doença meningovascular crônica, principalmente com o advento da AIDS (Davis, 2008).

É necessário ter em conta que, após o surgimento da AIDS e a consequente queda da imunidade destes pacientes, não há uma parte do neuroeixo imune à ocorrência de doenças infecciosas e suas complicações (Berger \& Dean, 2014). Wright et al. (1997) sugerem que os recursos da neuroimagem, quando somados à clínica e às descobertas laboratoriais, frequentemente favorecem o diagnóstico correto e habilitam o médico a iniciar a terapia.

Neste contexto, cabe ressaltar que a NS deve ser um diagnóstico diferencial em pacientes com meningite asséptica ou em situações de alterações de comportamento no paciente com HIV. A gravidade da doença, associada à demora no reconhecimento, diagnóstico e tratamento da NS, obriga, na percepção de Schiff \& Lindberg (2002), sua inclusão no diagnóstico diferencial de pacientes jovens com declínio cognitivo. Assim, em razão da ampla sintomatologia neuropsiquiátrica possível, o médico deve estar atento, na sua prática clínica, para a possibilidade de diagnosticá-la. 
Isso reforça a importância do exame clínico neuropsiquiátrico e a necessidade de realização de exames complementares como o VDRL e o líquido céfalo-raquidiano (LCR) (neste último caso, se forem observados síndrome neuropsiquiátrica e VDRL positivo). Esse conjunto de práticas possibilita diagnósticos precoces com repercussões positivas no tratamento e prognóstico, além de melhorar os indicadores epidemiológicos regionais.

\section{CLASSIFICAÇÃO}

A NS pode ser classificada de acordo com critérios cronológicos (precoce e tardia) ou clínicos (formas assintomática e sintomática). Quando a doença ocorre até o primeiro ano da infecção, temos a forma precoce e, após esse período, a forma tardia. Segundo os critérios clínicos, se são detectadas anormalidades no exame do LCR sem sintomatologia (casos de estudo de prevalência de positividade do VDRL no líquor), classificamos como forma assintomática (incluindo ausência de sintomas de funções pré-frontais e outras funções corticais); nos demais casos, temos a forma sintomática. Dentre as formas de NS sintomática, encontramos dois grandes grupos: parenquimatosas e meningovasculares. As formas parenquimatosas, mais tardias, incluem paralisia geral progressiva, tabes dorsalis, atrofia óptica e taboparalisia. As formas meningovasculares manifestam-se mais frequentemente como meningites subagudas afetando nervos cranianos, causando arterites como acidentes vasculares cerebrais ou como mielopatias progressivas (Waddington et al., 2011).

Com base em estudos anatomopatológicos, Motta e Espíndula (1998) relataram que raramente o acometimento neurológico ocorre numa forma isolada, já que todas as formas de NS são iniciadas por uma meningite sifilítica. Portanto, são observadas formas combinadas de meningite e sífilis vascular ou tabes dorsalis e paresia geral.

\section{QUADRO CLÍNICO}

A apresentação clínica atual da NS não segue a evolução tradicional da era pré-antibiótica (Mitsonis et al., 2008). As manifestações clínicas da paralisia geral progressiva (PGP) simulam qualquer tipo de transtorno mental, funcional ou lesional. A sintomatologia psíquica da NS carece, efetivamente, tanto de especificidade quanto de uniformidade, variando, assim, na sua expressão fenomenológica de acordo com as formas clínicas e com os diferentes períodos de sua evolução (Mitsonis et al., 2008).

A NS pode ser interpretada como uma "grande imitadora", isto é, pode apresentar quadros clínicos muito similares aos de outras enfermidades do sistema nervoso, podendo ser confundida, mesmo após anos de acompanhamento, com doenças neurológicas e psiquiátricas tais como: demência de Alzheimer, esclerose múltipla, tumores, doença de Parkinson, acidente vascular cerebral por arteriosclerose, esquizofrenia, depressão, etc. (O’donnell \& Emery, 2005). 
Estima-se que $85 \%$ do total de casos apresentaram as formas ditas típicas (Mitsonis et al., 2008):

Estima-se que $85 \%$ do total de casos apresentaram as formas ditas típicas (Mitsonis et al., 2008):

1. Forma demencial simples: início insidioso, rapidamente progressivo, havendo um prejuízoo global das funções cognitivas e ausência de sintomas produtivos.

2. Forma maníaco-depressiva: apresenta-se sob a forma de excitação maníaca. Ocorre perda da autocrítica, euforia, ideias de grandeza de proporções absurdas. É possível encontrar, ao invés disso, a instalação de um estado depressivo de conteúdo geralmente hipocondríaco e neurastênico.

3. Forma esquizofrênica: menos frequente que as anteriores, pode aflorar com um quadro paranoide, com ideias persecutórias ou de grandeza, mal sistematizadas, acompanhadas de fenômenos alucinatórios, visuais e auditivos, ou assumir a apresentação de uma síndrome catatônica.

4. Formas confusionais: evoluem com períodos de franca confusão mental, com pensamento incoerente, desorientação e alterações variadas da consciência. Podem ocorrer em associação com a história de dependência do álcool.

As formas atípicas descritas a seguir são mais raras e constituem cerca de $15 \%$ dos casos (Marra, 2009):

1. Paralisia geral de Lissauer: caracteriza-se pela abundante sintomatologia neurológica local (paresias, convulsões, síndrome cerebelar, etc.), salientando-se que o deficit demencial é sempre tardio e parcial.

2. Tabo-paralisia: trata-se de uma superposição de sintomas de paralisia geral em uma tabes preexistente.

3. Paralisia geral infanto-juvenil: expressão da sífilis congênita, iniciada entre os 10 e 20 anos de idade, adota quase sempre a forma neurológica.

4. Paralisia geral senil: inicia-se entre os 60 e 85 anos de idade e se faz acompanhar de sintomas neurológicos importantes como estado demencial bastante pronunciado.

A forma parética da NS pode ser considerada uma meningoencefalite progressiva que ocorre cerca de 10 a 20 anos após a infecção inicial não tratada. Em relação às manifestações clínicas, o início é insidioso, com deterioração sutil da cognição que se manifesta com dificuldade de concentração, irritabilidade, falta de interesse e discretas alterações de memória. Em muitos casos estes sintomas são diagnosticados erroneamente como depressão. Outras alterações podem não ser encontradas no exame neurológico. O quadro evolui de forma progressiva e pode mimetizar qualquer síndrome neuropsiquiátrica, mais frequentemente a demência associada a elementos paranoicos (delírios e alucinações) e a psicose maníaca. Com a progressão da doença, o paciente começa a apresentar hipotonia muscular, tremor de extremidades, disartria, convulsões, perda do controle de esfincteres e, finalmente, chegar à morte. Se não tratada, a doença progride de forma insidiosa em um período de 3 a 4 anos após a instalação da sífilis terciária (Ghanem, 2010). 
O quadro clínico da NS parética, em sua forma plenamente desenvolvida, é de desagregação mental e física progressiva, inclui tremores de ação, abalos mioclônicos, convulsões, hiper-reflexia, sinal de Babinski e pupilas de ArgyllRobertson. Sabe-se da importância do diagnóstico em fase mais precoce quando poucas dessas manifestações se fazem presentes (Mitsonis et al., 2008). As formas clínicas da NS, de acordo com o tempo da doença, apresentam estádios evolutivos do comprometimento do SNC (Figura 1).

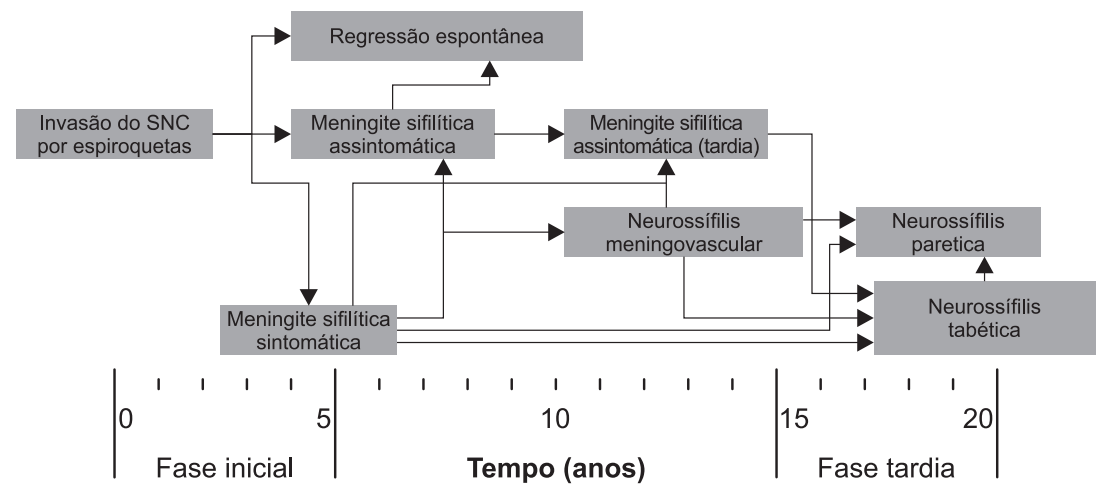

Figura 1. Diagrama da evolução da neurossífilis.

As publicações clássicas enfatizam o surgimento de delírios, mais claramente no sentido da megalomania, que são evidentes para a família e amigos e não o são em absoluto para o indivíduo envolvido. O mais comum é a presença de demência simples com enfraquecimento das capacidades intelectuais, esquecimento, distúrbios da fala e da escrita e preocupações vagas quanto à saúde (O’donnell \& Emery, 2005).

Os primeiros indícios de uma encefalite sifilítica lembram o delirium (confusão mental) ou uma encefalite viral aguda. Com a progressão da deterioração para o estágio paralítico, as funções cognitivas deterioram-se completamente e surgem afasias, agnosias e apraxias (O'donnell \& Emery, 2005).

\section{DIAGNÓSTICO}

O diagnóstico da sífilis e NS se faz por meio da anamnese, do exame clínico e da realização de exames complementares com base em análises do soro sanguíneo e do líquido céfalo-raquidiano (LCR). Existem as reações ditas não treponêmicas e as treponêmicas. As reações não treponêmicas incluem o VDRL e a reação de Wassermann. As reações treponêmicas incluem FTA-Abs, hemaglutinação e imunofluorescência (Harding \& Ghanem, 2012, Zerati, 2002). 
A avaliação laboratorial é de fundamental importância, pois este tipo de comprometimento neurológico pode estar presente em várias outras doenças. As provas sorológicas e as imunológicas no LCR são determinantes no diagnóstico da NS.

A primeira prova com antígeno treponêmico, denominada prova de imobilização de T. pallidum (TPI), foi descrita por Nelson e Mayer (1949). A TPI muito contribuiu para a elucidação das reações biológicas inespecíficas ou falso-positivas, mas pouco se difundiu na prática, em virtude de dificuldades na preparação do antígeno e do perigo de contágio por se tratar de treponemas patogênicos vivos (Harding \& Ghanem, 2012, Lima et al., 2001).

A positividade do VDRL contribui para a confirmação diagnóstica da NS, embora sua negatividade não nos permita excluir a possibilidade desta doença (resultados falso-negativos). Resultados falso-positivos podem ocorrer em razão da presença de sangue no líquor e também em decorrência da associação com doenças autoimunes (colagenoses, Tiroidite de Hashimoto) e gravidez. O VDRL pode estar negativo no início da infecção (primeiras quatro a oito semanas) e nas formas tardias da doença (Zerati, 2002).

Entre as reações treponêmicas, a mais utilizada é a análise do FTA-Abs. É um exame sensível e de elevada especificidade que traduz a infecção por Treponema pallidum. É indicado principalmente nos casos de dúvida quanto ao resultado do VDRL e em pacientes com sintomatologia de sífilis tardia, em que os testes não treponêmicos podem ser negativos. Resultados positivos do FTA-Abs, associados à positividade ou não do VDRL, nos conduzem à confirmação de ocorrência da sífilis. Se as reações treponêmicas forem negativas no soro, o diagnóstico de sífilis e de NS está praticamente excluído (O'donnell \& Emery, 2005, Zerati, 2002).

O exame do LCR é de extrema importância na confirmação diagnóstica da NS. Zerati (2002) considera que o LCR pode estar alterado a partir da infecção do SNC pelo agente etiológico. Anormalidades liquóricas são encontradas em até 40\% dos casos de sífilis secundária.

O diagnóstico da NS deve basear-se no conjunto de informações clínicas e laboratoriais, não havendo um teste com especificidade e sensibilidade absolutas. É difícil, segundo Nitrini (1981), determinar se houve modificações do quadro clínico da doença quando não existem critérios diagnósticos bem estabelecidos. Portanto, é importante frisar que todo processo de NS deve ter a assistência de um neurologista e todo paciente com esta suspeita clínica deve ser inquirido sobre irritabilidade excessiva, cefaleia, insônia, alterações na fala e na visão, anormalidades pupilares, alterações nos reflexos profundos, presença do sinal de Romberg, parestesias e crises viscerais.

\section{TRATAMENTO}

Até 1910, segundo relato de Pagnano e Bechelli (1987), não havia medicação eficaz no tratamento da sífilis. Usavam-se mercuriais e sais de iodo, 
contudo proporção considerável de doentes apresentava, em longo prazo, formas graves da doença (lesões destrutivas cutâneas e mucosas, lesões cardíacas e de grandes vasos e lesões neurológicas: tabes, paralisia geral progressiva, etc.). Os arsenicais começaram a ser utilizados a partir das pesquisas de Paul Ehrlich (1910) e mostraram ser agentes terapêuticos bastante eficazes, reduzindo a incidência da doença e o aparecimento de formas tardias. Porém, tinham a desvantagem de serem empregados em tratamentos longos (três a quatro anos), associados aos mercuriais e ao bismuto notadamente a partir de 1921 (Ehrlich apud U. S. Government Printting Office, 1964).

Em 1917, Wagner-Jauregg, citado por Storm-Mathisen (1978), introduziu a malarioterapia, que se mostrou mais eficiente que os demais métodos até então disponíveis para o tratamento da PGP. A malarioterapia, utilizada nos casos resistentes ou nas formas parenquimatosas da PGP, rendeu ao seu idealizador o Prêmio Nobel de Medicina.

A penicilina, descoberta por Fleming (1929), foi introduzida no arsenal terapêutico por Chain et al. em 1940 e utilizada, em solução aquosa, no tratamento de sífilis em 1943 por Mahoney, Arnold e Harris. A penicilina constituiu medicação de grande impacto por sua eficácia, simplicidade de uso, baixo custo, tempo de tratamento bastante curto e com menor possibilidade de reações colaterais.

Em um estudo com 62 pacientes submetidos a elevadas doses de penicilina cristalina intravenosa (24 milhões de unidades ao dia, sendo 4 milhões de 4/4 horas, durante 21 dias), Nitrini (1987) concluiu que é muito dificil definir um esquema terapêutico que seja eficaz em todos os casos de NS. Cada caso deve ser analisado individualmente e o acompanhamento depois do tratamento deve ser rigoroso para surpreender os casos nos quais ocorram falhas terapêuticas. $\mathrm{O}$ pesquisador concluiu ainda que os resultados da penicilinoterapia intravenosa em altas doses não diferiram daqueles obtidos com penicilinoterapia intramuscular em baixas doses registrados na literatura.

A literatura atual esclarece que quanto mais tardiamente for tratada a NS, maiores serão as sequelas cognitivas e comportamentais apresentadas. Apesar de ser considerada uma forma de demência reversível, observamos, na prática, que o curso do processo demencial é efetivamente interrompido, porém o paciente não recupera integralmente suas funções corticais superiores, permanecendo sequelas de prejuízo cognitivo e comportamental.

\section{REFERÊNCIAS}

1. Berger JR, Dean D. Neurosyphilis. Handb Clin Neurol 121: 1461-1472, 2014.

2. Chain E, Florey HW, Gardner AD, Heatley NG, Jennings MA, Orr-Ewing J, Sanders AG. Penicillin as a chemotherapeutic agent. Lancet 2: 226-228, 1940.

3. Davis G. Aetiology and social epidemiology. Neurosyphilis. Clio Medica 85: 199-238, 2008.

4. Ehrlich P. Diskussionsbemerkungen zum Vortrag von Wechselmann (Chemotherapie der Syphilis). Bericht ueber die Tagung der Freien. Vereinigung fur Mikrobiologie 47: 223-224, 1910. 
5. Fleming A. On the antibacterial action of cultures of a penicillium, with special reference to their use in the isolation of B. influenzae. Br J Exp Pathol 10: 226-236, 1929.

6. Fournier A. Traité de la Syphilis. J. Rueff Ed., Paris, 1906. t. 1, f. I.

7. Fournier A. Die Syphilis des Gehirns. Vierteljahresschrift für Dermatologie und Syphilis 6: 589-601, 1879.

8. Gastal FL, Leite SSO, Andreoli SB, Gameiro MA, Gastal CL, Gazalle FK, Crema FB. Tratamento etiológico em psiquiatria: o modelo da neurossífilis. Rev Bras Psiquiatr 21: 29-35, 1999.

9. Ghanem KG. Review: Neurosyphilis: A historical perspective and review. CNS Neurosci Ther 16: 157-168, 2010.

10. Harding AS, Ghanem KG. The performance of cerebrospinal fluid treponemal-specific antibody tests in neurosyphilis: a systematic review. Sex Transm Dis 39: 291-297, 2012.

11. Lima AO, Soares JB, Greco JB, Galizzi J, Cançado JR. Diagnóstico Sorológico da Sífilis. In: Métodos de Laboratório Aplicados a Clínica - Técnica e Interpretação. 8. ed. Rio de Janeiro, Ed. Guanabara Koogan, 2001. p. 15-18.

12. Marra CM. Update on neurosyphilis. Curr Infect Dis Rep 11: 127-134, 2009.

13. Mitsonis CH, Kararizou E, Dimopoulos N, Triantafyllou N, Kapaki E, Mitropoulos P, Sfagos K, Vassilopoulos D: Incidence and clinical presentation of neurosyphilis: a retrospective study of 81 cases. Int J Neurosci 118: 1251-1257, 2008.

14. Mota RN, Espindula IA. Sífilis e mielopatia no paciente com HIV/Aids. Uma abordagem atual. Rev Bras Clín Terap 24: 26-100, 1998.

15. Nelson RA, Mayer MM. Immobilization of Treponema pallidum in vitro by antibody produced in syphilitic infection. J Exp Med 89: 369-393, 1949.

16. Nitrini,R. Neurossífilis - análise de alguns aspectos clínicos e laboratoriais; São Paulo, 1981. 147p. Dissertação (Mestrado) - Faculdade de Medicina, Universidade de São Paulo.

17. Nitrini R, Spina-França A. Penicilinoterapia intravenosa em altas doses na neurossífilis - estudo de 62 casos. Arq neuropsiquiatr 45: 99-108, 1987.

18. O'donnell JA, Emery CL. Neurosyphilis: A Current Review. Curr Infect Dis Rep 7: 277-284, 2005.

19. Pagnano PMG. Bechelli LM. Alguns aspectos psicológicos e sociais relacionados com a sífilis. $J$ Bras Psiq 36: 271-274, 1987.

20. Schiff E, Lindberg M. Neurosyphilis. South Med J 95: 1083-1087, 2002.

21. Storm-Mathisen A. Syphilis. In: Vinken PJ \& Bruyn GW ed. Handbook of clinical neurology. Amsterdam, North Holland Publishing, 1978. p. 337-394.

22. Timmermans M, Carr J. Neurosyphilis in the modern era. $J$ Neurol Neurosurg Psychiatry 75: 1727-1730, 2004.

23. U.S. Government Pritting Office, Washington, DC. Proceedings of the World Forum on Syphilis and Other Treponematoses. Public Health Service Publication, n. 997, 1964.

24. Waddington K, Thomas R, Willis M. General paralysis of the insane. Pract Neurol 11: 366-369, 2011.

25. Wright D, Schneider A, Berger JR. Central nervous system opportunistic infections. Neuroimaging Clin N Am 7: 513-525, 1997.

26. Zerati. Neurossífilis. Disponível em www.neuroradiologiaonline.com.br/zerati/neuro/sifilis/htm. Acesso em 29 mai. 2004.

27. Zhang HL, Lin LR, Liu GL, Zeng YL, Wu JY, Zheng WH, Tong ML, Dong J, Su YH, Liu LL, Yang TC. Clinical spectrum of neurosyphilis among HIV-negative patients in the modern era. Dermatology 226: 148-156, 2013. 